\section{Feeling the difference}

\section{Stuart Sutherland}

Descartes' Error: Emotion, Reason and the Human Brain. By Antonio R. Damasio. Grosset/Putnam: 1994. Pp. 312. \$24.95.

EMOTION is almost impossible to define, there is no agreement about what it is, we do not know what it is for and we are unsure what to include in it - are hunger, boredom and curiosity emotions? It is small wonder that cognitive science, neuroscience and artificial intelligence have largely ignored it. Descartes' Error is a spirited attempt to rectify this omission.

Antonio Damasio believes unexceptionably that emotions involve cognition, efferent output and feedback from the resulting changes in the autonomic and hormonal systems, and in the skeletal musculature (as in a smile or a frown). These effects are accompanied by the release of neurotransmitters in the brain. Damasio distinguishes primary emotions (which are innately triggered and include hunger, fear of snakes, and sexual desire) and "secondary ones", which he believes result from the formation of "systematic connections between categories of objects and situations... and primary emotions".

So far, so good: the account is well argued, but not particularly novel. Damasio's original contribution is his hypothesis about what emotion is for. The evolutionary value of the primary emotions is obvious. $\mathrm{He}$ argues, however, that the bodily feedback - which he calls a "somatic marker" - from secondary emotions prevents anyone making a decision from contemplating possible courses of action that would lead to bad consequences. At first this sounds far-fetched, particularly as much decision-making does not involve strong feelings. But Damasio meets this objection by postulating that the brain can bypass feedback from the periphery by itself bringing about patterns of activity similar to those that genuine sensory feedback produces: he terms this an "as if" emotion.

He gives impressive evidence for his suggestion. Characterizing the defects that arise from prefrontal lobe lesions has for long been a difficult problem. One of Damasio's own patients who was subjected to a large number of mental tests, including tests of intelligence, personality and moral reasoning, was normal on all of them. Yet his behaviour was far from normal. He was so distractible that he was unable to hold down a job and he vacillated wildly over personal decisions. Furthermore, his emotions were shallow. Damasio concludes that because in this patient and other people with prefrontal lesions the consideration of bad options is not nipped in the bud by an emotional reaction, they are incapable of taking and sticking to decisions. Moreover, as he suited to combine emotional feelings and cognition, for it receives an input from the sensory areas of the brain, including the somatic areas, from association areas and from those parts of the limbic system known to be implicated in emotion and primitive drives.

Damasio's most interesting evidence, however, comes from two experiments in which he compared the galvanic skin response of normals and prefrontals. In his first experiment, he showed his subjects pictures, most of which were emotionally neutral, but some of which were scenes that would be expected to arouse strong emotion. To the latter set of pictures, normals gave large galvanic skin responses, whereas the prefrontals gave none, even though they could describe the emotions that the pictures would normally produce, such as fear, disgust or sadness. These results suggest that the prefrontal lobe is implicated in secondary emotion, for the prefrontals gave normal galvanic skin responses to stimuli producing primary emotions, such as a startle stimulus.

The second experiment lends even more direct support to Damasio's hypothesis. Subjects were asked to select a card from one of four piles. Initially they received a reward if they picked a card from the first two of the four piles and a lower reward if they selected cards from the other two. Subsequently, they sometimes suffered a very large loss if they picked cards from the first two piles. Normal subjects correctly switched to the less risky piles, prefrontals did not. Damasio concludes that it is the somatic marker that prevents the normal subjects from picking cards from the dangerous piles: prefrontals continued to do so because the emotional warning of danger was with caution since it is known that prefrontal patients are bad at switching responses even in situations where little or no emotion is involved.

There were, however, two further important findings. After their first experiences of large losses but before they were conscious that some piles were more remunerative than others, the normal subjects would sometimes pick a risky card and on these occasions they showed a galvanic skin response immediately before doing so. Damasio suggests that the emotional response (the somatic marker) had been learned unconsciously before the subjects were consciously directing their observes, the prefrontal cortex is ideally absent. This conclusion should be treated choice correctly. The operation of somatic markers on unconscious thought processes would explain correct intuitions: mathematicians tend to consider consciously only lines of thought that might be fruitful; the others are unconsciously blocked by somatic markers. Finally, it is of interest that although the prefrontals persisted with a poor strategy, some of them were later able to say that the risky piles were bad and the others better: conscious knowledge is not enough to direct choice in the absence of somatic markers.

These fascinating results (and some equally striking findings obtained since his book was written) provide strong support for Damasio's hypothesis. Moreover, in addition to the evidence adduced by Damasio himself, there are some surprising findings - from a different field that suggest emotion is involved in cognition: people are better at remembering and recognizing faces when they are instructed to concentrate on their emotional impact rather than on their physical form.

Damasio's own arguments are ingenious and wide ranging: they have been given only the barest sketch here. Only neurophysiological work could disprove his theory, because of his introduction of that Catch 22 - unobservable "as if" emotions. A cynical psychologist might argue that Damasio's basic hypothesis is that people perform actions that are likely to have agreeable consequences and avoid those that have disagreeable ones, but Damasio could rightly retort that it is the neurophysiological mechanism that is important. His thoughtful and modest exposition should be taken seriously. Apart from illuminating the function of parts of the frontal lobes, he has proposed a new physiological mechanism that is likely to be much investigated over the next few years. It is no mean feat to say something original and intelligible about emotion.

Stuart Sutherland is in the Laboratory of Experimental Psychology, University of Sussex, Brighton BN1 9QG, UK.

\section{New in paperback}

The Life of Isaac Newton by Richard Westfall. Canto (Cambridge University Press), $£ 7.95$ $\$ 11.95$. An abridged version of his monumental biography Never at Rest, first published in 1980. "Westfall is a lively and lucid expositor of Newton's ideas and he has written an excellent book for those who want an authoritative introduction" (William R. Shea, Nature 364, 681; 1993).

The Golem: What Everyone should know about Science. By Harry Collins and Trevor Pinch. Canto (Cambridge University Press), $£ 5.95$, \$9.95. "Perverse but entertaining.. the writing is deft, the stories are good, and there is not a boring page" (Walter Gratzer, Nature 364, 22; 1993). 